\title{
Contra o juízo: \\ Benjamin e a tarefa da crítica de arte como tradução
}

\author{
Against Judgment: \\ Benjamin and the task of art criticism as translation
}

\author{
João Pedro Cachopo \\ Universidade Nova de Lisboa
}

\begin{abstract}
Resumo: A tensão entre uma concepção ora positiva ora negativa da crítica - tipicamente associadas à "crítica de arte" e à "crítica da ideologia" - atravessa a obra de Benjamin de lés a lés, sendo que esclarecê-la é decisivo para compreender o modo como o filósofo e crítico alemão entende a relação entre arte e política no contexto do debate sobre a vanguarda. Solidário com este esclarecimento, o presente artigo ensaia uma aproximação entre as ideias de "crítica de arte" e de "tradução" - com base no ensaio de Benjamin sobre "A tarefa do tradutor" - com o objetivo de esclarecer a irredutibilidade da tarefa do crítico de arte às suas dimensões judicativa e hermenêutica. O sentido e a pertinência desta proposta tornam-se mais claros à luz do paradoxo da traduzibilidade. Segundo Benjamin, uma obra é tanto mais traduzível quanto mais a sua tradução é difícil (i.e., quanto mais ela obriga o tradutor a alargar a língua de chegada para restituir o "modo de querer dizer" do original). A esta luz, afirmar que a tarefa do tradutor permite iluminar a do crítico equivale a insistir em dois pontos: por um lado, em que cabe ao crítico desdobrar de modo positivo o objeto criticado, sem recorrer a um saber que lhe permitisse corrigir o artista ou orientar o espectador/leitor/ouvinte; por outro lado, em que a sua atenção deve incidir sobretudo nos elementos negativos da obra, naquilo cuja irredutibilidade à interpretação a torna a um só tempo suscetível e digna de ser criticada.
\end{abstract}

Palavras-chave: crítica; tradução; Benjamin; juízo; interpretação; espectador; Rancière.

Abstract: The tension between positive and negative notions of critique - typically associated with art criticism and the critique of ideology - marks the work of Benjamin throughout his career. Also, its clarification is crucial to understand the way in which the German philosopher and critic approaches the relationship between art and politics with regard to the debate about the avant-garde. At one with such a clarification, the present article attempts to bring closer the ideas of "art criticism" and "translation" - drawing on Benjamin's "The task of the translator" - with the aim of shedding light on the irreducibility of the art critic's task to its judgemental and hermeneutic dimensions. The sense and relevance of such a focus becomes clearer in the light of the paradox of translatability. According to Benjamin, a work is all the more translatable, the more it proves to be hard to translate (i.e., the more it forces the translator to expand the target language in order to render the "the way of meaning" of the original). In this light, to claim that the task of the translator enlightens that of the critic is tantamount to stressing two points: firstly, that it is up to the critic to unfold, in a positive way, the object criticized, without relying on any knowledge that would entitle her/him to rectify the artist or guide the spectator; secondly, that he/she should focus on the negative elements of the work, those whose irreducibility to interpretation make it at once capable and worthy of criticism. 
Keywords: criticism; translation; Benjamin; judgment; interpretation; spectatorship; Rancière.

A situação ideal é aquela em que o crítico se esquece de emitir um juízo.

Walter Benjamin

1.

Entre os vários fatores que permitem explicar a resistência à crítica, há um que - nada devendo ao cinismo de que tantas vezes tal resistência mais não é do que uma máscara merece ser explicitado. Eis a suspeita: que o crítico se posicione paulatinamente acima daqueles e daquelas cujas ilusões teria por tarefa dissipar faria dele um promotor, não da emancipação, mas do embrutecimento de outrem. Ora, a emancipação, consideremo-la uma arte maior (como Kant) ou menor (como Deleuze) ${ }^{1}$, tem na rejeição de qualquer tipo de tutela um dos seus fios condutores mais longos e persistentes. Foucault (1990, p. 35-63) reconheceu-o, desde logo, nas práticas de resistência à pastoral cristã; Agamben (2011), mutatis mutandis - e não ignoramos que a remissão do seu pensamento para os tópicos da crítica e da emancipação seria considerada abusiva pelo próprio - nas práticas da regra franciscana. Já Rancière, por seu turno, vê na emancipação um processo cuja lógica é inseparável da contestação da autoridade do mestre (sobre o discípulo), do teórico revolucionário (sobre o proletário), do crítico da sociedade do espectáculo (sobre, enfim, a multidão de pessoas que nela participariam sem saberem). Contudo, mais do que uma "crítica da crítica", está em jogo para o autor d'O Mestre Ignorante e d'O Espectador Emancipado a desmontagem do mecanismo embrutecedor que impede a tomada de consciência de que a emancipação está ao alcance de qualquer um. Que a crítica possa enfim exercer-se como uma arte da emancipação e não do embrutecimento seria então o desafio.

\section{2.}

No campo da arte, a ideia de um retorno da ou à crítica é particularmente ambíguo. Ao evocálo, pode ter-se em mente ora as práticas artísticas propriamente ditas ora os discursos que as tomam por referência ou ponto de partida. Num caso, é ao próprio potencial crítico, político ou transgressor da arte que se alude; no outro, à acutilância de um discurso crítico - parcial, apaixonado, político, como o caracterizou Baudelaire ${ }^{2}$ e como hoje conviria recuperar - sobre o vigor ou a debilidade das práticas artísticas. É verdade que estas duas declinações da crítica se relacionam de múltiplas formas. E não é absurdo acrescentar que podem reforçar-se mutuamente. Tal pode, de fato, acontecer. Mas não acontece necessariamente. Aliás, pode igualmente suceder que os dois movimentos - a revitalização do ímpeto crítico da arte, num

\footnotetext{
${ }^{1}$ A propósito da tensão entre dois paradigmas de emancipação - um maior associado a Kant, outro menor associado a Deleuze -, leia-se L'émancipation de Kant à Deleuze de Diogo Sardinha (2013).

${ }^{2}$ Por exemplo, em "À quoi bon la critique” (2001 [1846], p. 641): “[...] para ser justa, quer dizer, para ter uma razão de ser, a crítica deve ser parcial, apaixonada, política, quer dizer feita de um ponto de vista exclusivo, mas do ponto de vista que abre o maior número de horizontes". Salvo indicação em contrário, as traduções incluídas neste texto são da responsabilidade do autor.
} 
caso, e o refortalecimento da crítica de arte, no outro - não só não se reforcem como entrem em rota de colisão.

Por um lado, assiste-se à reinvenção de estratégias artísticas, de carácter participativo, colaborativo e/ou relacional, cujas motivações políticas são evidentes. A descrença na capacidade subversiva da arte foi perdendo, também ela, os seus crentes. E são muitos os sinais de que a vontade dos e das artistas de intervirem no mundo que os e as rodeia está na ordem do dia (e isto independentemente do êxito que possam ou não ter as suas propostas concretas). É neste sentido que se pode falar de um retorno da crítica $d a$ arte. Por outro lado, no que toca à crítica de arte, espera-se do crítico uma renovada acutilância - quer dizer, que não permaneça neutro, que tome posição, que seja parcial. Claro que uma tal parcialidade não seria fruto de impressões arbitrárias, pelo que se poderia associá-la a uma espécie de espontaneidade amadurecida pela experiência e pela reflexão continuadas no campo das artes. Destas decorreria a legitimidade da atividade crítica, a qual, para além disso, justificaria a expectativa de que o crítico não se limite a descrever ou a explicar: de que ele, pois bem, ouse julgar.

É este corolário, a ideia de que a revitalização da crítica de arte se cumpre na assunção do papel de juiz pelo crítico, que nos parece altamente problemático. Não se elevaria assim o crítico a um patamar superior ao ocupado por artistas e espectadores, dando azo a uma hierarquia entre uns e outros que compromete de antemão a dimensão emancipatória da crítica (da crítica $d a$ própria arte)? Tocamos numa dificuldade próxima da referida no início deste texto - próxima, mas não análoga, em virtude do paradoxo que desta feita se insinua. Reconhecendo-se à própria arte um potencial crítico, faz-lhe justiça uma crítica de arte reconduzida à sua função judicativa? Por outras palavras: pode um crítico desdobrar o potencial crítico de uma arte tendente a problematizar o que se sabe sobre o real, supondo-se a priori detentor de um saber que permite avaliá-la?

Nenhuma destas questões é inteiramente nova. Para Friedrich Schlegel ou Novalis, recuando aproximadamente dois séculos, a crítica ou é imanente ou é um equívoco. A obra de arte geraria a sua própria "criticabilidade", enquanto desdobramento e acabamento de si mesma. Já Goethe rejeita por completo a noção de crítica, acusando-a de manter o espectador na soleira da obra de arte, de onde só as suas características extrínsecas seriam apreciáveis. Curioso, portanto, é que os românticos e Goethe divirjam no tocante às teses que defendem favoráveis ou desfavoráveis à "criticabilidade" da arte - por força de uma intuição em que convergem plenamente: a arte não pode ser criticada a partir de fora ${ }^{3}$. O que também quer dizer, numa formulação mais próxima de F. Schlegel, que a crítica de arte mais não é do que autorreflexão e autocrítica da obra de arte. Estas formulações são suficientemente desconcertantes para gerar o caos na mesa de trabalho de muitos teóricos para quem o critério da crítica não pode não ser exterior ao objeto criticado... Pois, caso contrário, a crítica incorreria - é como se diz pelas bandas de Frankfurt desde os tempos de Habermas - num "défice normativo".

Devemos a Walter Benjamin a revisitação do conceito de crítica de arte romântico, à luz do qual não é fácil destrinçar o zelo dos advogados de uma concepção normativa de crítica da mais pura retórica filisteia. Desenvencilhemo-nos desta retórica e daquele zelo. Sim, a crítica de arte tem uma dimensão valorativa ou axiológica indesmentível. Aliás, aquilo que o entendimento positivo da crítica de arte romântica pressupõe, segundo Benjamin, não é tanto a imunidade dos objectos artísticos a uma apreciação negativa quanto à convicção de que a crítica só se torna verdadeiramente possível quando uma apreciação positiva se revela

\footnotetext{
${ }^{3}$ Sobre o contraste e a afinidade entre as perspectivas de Goethe e dos românticos, no que toca à questão da crítica e ao pensamento de Benjamin, leia-se O Químico e o Alquimista de Maria Filomena Molder (2011, p. 5566).
} 
acertada, quando o crítico encontra o "criticável"4. Mas isto - assumir a dimensão axiológica da crítica de arte - não significa justamente - é aí que reside o equívoco - que a tarefa do crítico de arte se cumpra enquanto tal na formulação de juízos, de censura ou de aprovação. Isto não obsta, antes pelo contrário, ao carácter apaixonado da crítica, que, decerto, pode e deve, nas mais diversas circunstâncias, ter uma dimensão polêmica e, nesse sentido, conduzir a formulações judicativas. De resto, que a crítica não se possa resumir ao juízo mostra-o melhor do que qualquer outra coisa a insuficiência de uma crítica favorável - mas insípida, descarnada, desapaixonada... Por estranho que pareça, uma crítica desfavorável - mas entusiasticamente desfavorável, batendo-se polemicamente com os diferentes momentos do objeto criticado - pode dizer mais sobre o seu potencial do que uma crítica favorável sem rasgo nem paixão ${ }^{5}$.

O que isto mostra é que o "sentido" da crítica - positivo ou negativo - não capta o seu "teor". O que isto, além disso, sugere é que a obsessão pelo momento normativo da crítica a empobrece: o mais relevante passa-se a outro nível - um em que uma atenção cheia de incertezas, tateante, porém nem indiferente nem arbitrária, dá o mote à escrita. Pois é também de escrita que se trata, inevitavelmente, na crítica. Neste sentido, a arte da tradução - bem mais do que a faculdade do juízo - estaria no âmago da crítica. A tradução, no entanto, numa acepção peculiar que importará precisar mais adiante. Para desdobrar esta intuição, resgatando-a ao destino mais do que certo deste tipo de formulação lapidar - que é ser interpretada como uma mera força de expressão -, recorrerei a outro texto de Walter Benjamin. Já não ao Conceito de Crítica de Arte no Romantismo Alemão (1920), mas ao ensaio, da mesma época (escrito em 1921 e publicado, como prefácio à tradução de "Tableaux parisiens" de Baudelaire, em 1923), "A Tarefa do Tradutor".

\section{3.}

Que seja legítimo - e porventura inevitável - relacionar as tarefas do tradutor e do crítico sugere-o o próprio Benjamin ao escrever que a atividade de ambos representa "um momento da persistência vital das obras [Fortleben der Werke]" (1990 [1923], p. 15) ${ }^{6}$. A tradução, ainda mais do que a crítica, na medida em que se relacionaria intimamente com o "grande motivo de uma integração das várias línguas numa língua verdadeira” (1990 [1923], p. 16). Que, neste contexto, "A tarefa do tradutor" represente na obra de Benjamin, nas palavras retrospectivas do próprio, "uma primeira síntese das minhas reflexões sobre a teoria da linguagem" (1992, p. 232) torna-se óbvio em relação com outros textos da mesma época. Mas não nos obriga - nem, de resto, obrigou Benjamin - a desdobrar algumas das suas intuições aí contidas à luz dos pressupostos da teoria da linguagem, vinculada à ideia de "língua pura", que neste ensaio as enquadra. No presente texto, mais concretamente, tratar-se-á não tanto de explorar a afinidade entre as tarefas do tradutor e do crítico, consideradas na sua

\footnotetext{
${ }^{4}$ Leia-se, em particular, este passo: "o julgamento de uma obra [Beurteilung eines Werkes] nunca pode ser explícito, pois não pode senão estar implícito no facto da crítica romântica da obra (isto é, no facto da sua reflexão). Pois o valor da obra depende única e exclusivamente de ela tornar ou não possível a sua crítica imanente. Se esta for possível - se, portanto, estiver presente na obra a reflexão que em si mesma se desdobra, absolutiza e resolve no medium da arte - então trata-se de uma obra de arte" (1990 [1920], p. 78-79).

${ }^{5}$ Emblemático desta situação paradoxal é o chamado "caso Wagner", em que uma série de textos polémicos evoquemos os de Nietzsche, Mallarmé, Adorno, Mann, ou Lacoue-Labarthe... - tornaram manifesta, mais do que duvidosa, a relevância artística da obra do compositor de Tristão e Isolda.

${ }^{6}$ As versões em língua portuguesa dos excertos d'“A tarefa do tradutor" que pontuam este texto devem muito à tradução que dele fez Maria Filomena Molder (tradução que não está publicada e cuja partilha gostaríamos de agradecer mais uma vez à autora).
} 
especificidade linguística, quanto de tomar essa afinidade como pedra-de-toque para reuni-las numa figura conceptual: o crítico-tradutor.

Propõe Benjamin, a páginas tantas do seu ensaio, que a tarefa do tradutor "consiste em encontrar na língua em que se faz a tradução a intenção a partir da qual se ressuscita nessa língua o eco do original" (1990 [1923], p. 16). E não é isto, em larga medida, o que faz o crítico - encontrar os meios capazes de restituir na sua "língua", que é também a do hipotético leitor da crítica, o eco do original? Com esta pergunta, desloca-se decididamente a questão da tradução para o campo da crítica, pois que por "língua" não entendemos já "alemão", "francês" ou "português", mas, por um lado, a linguagem das artes - que pode ser integral ou parcialmente visual e/ou sonora - e, por outro, a linguagem da crítica - que, independentemente da língua em que esteja escrita, permanece fiel ao medium linguístico. Eis, pois, a pergunta: dir-se-á então que o "crítico-tradutor", distinto do "crítico-juiz", seria uma espécie de mediador entre a "língua" das artes e a "língua" dos seus espectadores, leitores e ouvintes? Para já, não confirmaremos nem infirmaremos esta perspectiva. Consideremos antes este excerto inicial do ensaio de Benjamin.

Vale uma tradução para os leitores que não compreendem o original? Isto parece bastar para esclarecer a diferença de categoria no domínio da arte entre ambos. Além disso, parece ser a única justificação para tornar a dizer "o mesmo". O que "diz" um poema? O que comunica? Muito pouco para quem o compreende. O que lhe é essencial não é nem comunicação nem mensagem. Por isso aquela tradução que quer servir de intermediário, não é intermediário de nada a não ser da comunicação - i.e., de algo inessencial. Isto é um sinal de identificação das más traduções. $\mathrm{O}$ que existe num poema para além da comunicação - e mesmo o mau tradutor admite que é isso o essencial - não se revelará em geral o inapreensível, o misterioso, o "poético"? Algo que o tradutor só pode restituir - poetando também? Disto decorre uma segunda marca da má tradução, que cabe definir enquanto transmissão imprecisa de um conteúdo inessencial. E assim permanecerá, enquanto a tradução se empenhar em servir o leitor. Mas, se ela estivesse destinada ao leitor, também o original teria de estar. Não estando o original nessa disposição, como haveríamos de compreender a tradução a partir dessa relação?

A tradução é uma forma. Entendê-la como tal implica regressar ao original. Pois no original está a lei da sua forma, enquanto contida na sua traduzibilidade [Übersetzbarkeit]. (Benjamin, 1990 [1923], p. 9)

Uma coisa é certa: se o crítico é um tradutor, não o é - retomando a nossa hipótese à luz desta passagem - na medida em que intervém como intermediário. É o que implica a ideia, crucial para Benjamin, de que a tradução não está meramente ao serviço do leitor incapaz de ler o original; uma ideia que, pensando no nosso crítico-tradutor, nos impede de equipará-lo a um facilitador de informações acerca do objecto artístico ou dos contextos, motivações ou propósitos subjacentes à sua produção. Ao mesmo tempo, continuando a seguir a pista de Benjamin, se a tarefa do tradutor tem um propósito próprio - se a tradução é uma forma - é preciso distingui-la da tarefa do poeta. Traduzir, tal como criticar, não é poetar. A tradução, ao contrário da poesia, teria na traduzibilidade do texto traduzido a sua lei. Pelo que não seria a poeticidade da tradução que a resgataria ao malfadado destino da tradução meramente explicativa. $\mathrm{O}$ mesmo se poderá dizer da crítica, cuja artisticidade mais não faria do que condenar à irrelevância. Assim, caberia ao crítico-tradutor regressar ao original - à lei contida, de modo imanente, na sua criticabilidade-traduzibilidade.

Ou seja, se a aproximação entre as tarefas da crítica e da tradução nos é útil, é-o, num primeiro momento, na medida em que nos permite desvincular a ideia de crítica da noção de juízo sem nos obrigar a equiparar o crítico ora a um intermediário (entre o artista e $\mathrm{o}$ espectador) ora a um substituto (do próprio artista). Por outras palavras, que o crítico enquanto tradutor, à luz de como Benjamin concebeu a sua tarefa - se abstenha de julgar não 
significa que ele se limite a comunicar informações acerca da estrutura do objeto, do contexto da sua produção ou da carreira do artista. Nem a avaliação nem a explicação serviriam de mote à crítica, sendo a irredutibilidade a ambas o que a aproximação à tradução permite desde logo esclarecer.

Contudo, a vantagem de um confronto com o ensaio de Benjamin vai muito além da explicitação desta irredutibilidade. Ela diz respeito, no seu sentido mais fértil, ao modo como Benjamin concebe e defende - de modo altamente heterodoxo, como veremos - o regresso ao "original" (i.e., à tal lei contida na sua traduzibilidade). Para evitar equívocos, importa esclarecer de imediato que, ao falar de original, Benjamin não tem em mente a configuração textual de uma obra literária tal como se fixou na época da sua produção: daí afirmar que a tradução provém não tanto da "vida" [Leben] quanto da "sobrevida" [Überleben] do original. Dito isto, a inexaurível distância entre a ênfase benjaminiana no original e um qualquer positivismo só se tornará nítida à luz da reinterpretação da dicotomia entre "fidelidade" e "liberdade" (tomadas como princípios orientadores da tarefa do tradutor).

À primeira vista, a posição de Benjamin parece assumir a forma de uma dupla negação: nem a fidelidade "à letra" [Treue gegen das Wort] nem a liberdade "para restituir o sentido" [Freiheit der sinngemäßen Wiedergabe] (1990 [1923], p. 17) permitiriam captar o que está em causa na boa tradução. Se, desta perspectiva, não se erra ao reconhecer que os dois princípios tendem a opor-se - i.e., que a fidelidade à letra dificulta a restituição do sentido - também não se acerta ao procurar reconciliá-los. É que, para Benjamin, o modo mais habitual de ultrapassar o impasse entre fidelidade e liberdade - que consiste em defender que a liberdade para com a letra pode reverter a favor da fidelidade ao sentido - acaba por servir de justificação para más traduções. Nestas, a boa tradução é confundida com a tradução idiomática, aquela sobre a qual se pode dizer, ironiza Benjamin, "que se lê como se estivesse no original" (1990 [1923], p. 18). O que, nestes casos, faz fracassar o tradutor é óbvio: reter da intenção original sobretudo "o que se quis dizer" [das Gemeinte] em prejuízo do "modo de querer dizer" [die Art des Meinens] (1990 [1923], p. 14). Ora, não sendo estes equiparáveis, é ao "modo de querer dizer" e não ao "que se quis dizer" - por outras palavras, ao "como" e não ao "quê" do sentido - que importa ser fiel, sob pena de reduzir a intenção poética a um mero significado comunicável.

Para explicitar este contraste, Benjamin recorre às palavras "Brot" e "pain" (1990 [1923], p. 14). Apesar de quererem dizer o mesmo (isto é, em português, "pão"), dizem-no de um modo manifestamente distinto, pois diferem as experiências associadas ao seu uso nas respectivas línguas. Podemos acrescentar a este exemplo a tradução proposta por Beckett, várias décadas mais tarde, de um passo do poema "Le bateau îvre" de Rimbaud. Considere-se a sua quarta estrofe:

[...] La tempête a béni mes éveils maritimes.

Plus léger qu'un bouchon j'ai dansé sur les flots

Qu'on appelle rouleurs éternels de victimes,

Dix nuits, sans regretter l'oeil niais des falots! [...]

[...] I started awake to tempestuous hallowings.

Nine nights I danced like a cork on the billows, I danced

On the breakers, sacrificial, for ever and ever,

And the crass eye of the lanterns was expunged. [...]

Ao optar por traduzir "dix nuits" por "nine nights" (destacados acima em itálico), é claramente ao "modo de significar" - aqui coincidente com o valor aliterativo - de "dix nuits" que Beckett confere primazia; não ao seu significado, restituível de forma permutável por "ten nights", "dez noites", etc. "Oito noites" talvez surta um efeito similar em língua portuguesa. 
[...] Despertei com o favor de revoltas marítimas.

Oito noites, mais leve que um lenho, dancei

sobre as vagas, baloiço eterno de vítimas,

a o vão tremeluzir dos faróis desprezei. [...]

O que entretanto se torna manifesto é que a rejeição em bloco da fidelidade e da liberdade não é a última palavra de Benjamin no que toca à tradução. De certo modo, Benjamin acaba por favorecer o princípio da fidelidade. Trata-se, no entanto, de repensar a ideia de fidelidade para além - e não aquém - da "restituição de sentido" [Widergabe des Sinnes] (1990 [1923], p. 17), no que ela acabará por reencontrar a noção de liberdade. Literal, no sentido da "exigência de literalidade" [Forderung der Wörtlichkeit] (1990 [1923], p. 18) preconizada por Benjamin a páginas tantas, seria a tradução que, por força da fidelidade ao "modo de significar" da língua de partida, conduz ao alargamento da língua de chegada, sendo neste alargamento que se manifesta a suprema liberdade do tradutor.

Retomemos a nossa hipótese para pesarmos em todas as suas implicações a aproximação entre as tarefas da crítica e da tradução. Decorre de tudo o que se disse até aqui que ao crítico caberá traduzir, não o "significado", mas o "modo de significar" do objeto criticado-traduzido. Que a tarefa do crítico-tradutor, distinto do crítico-juiz, não seja também a da "restituição de sentido" significa que a sua fidelidade ao objeto criticado-traduzido se joga, não só ao arrepio do positivismo (da literalidade em sentido estrito), mas também da hermenêutica. Esta precisão é da maior importância. Afinal, que para distinguir a atividade do crítico da atividade do juiz não se tivesse equipará-lo a um comunicador - foi o que vimos à entrada deste segundo ponto - não excluía a hipótese de que a sua verdadeira vocação fosse afinal a do hermeneuta: já não um amigável guia de museu, sempre solícito a fornecer informações úteis acerca da vida e do trabalho do artista, mas um verdadeiro Caronte capaz de iluminar o caminho do leitor-espectador pelas profundezas do sentido da obra.

Considere-se, a este propósito, a intuição que o próprio Benjamin toma de empréstimo a Rudolf Pannwitz: tal como não se trata, ao traduzir um poema do indiano, do grego ou do inglês para o alemão, de germanizar o indiano, o grego ou o inglês (i.e., de reconduzir estas línguas àquela), mas de indianizar, helenizar e anglicizar o alemão (de alargar esta língua através daquelas) (1990 [1923], p. 20), não se trataria também, ao criticar e traduzir um objeto artístico, de compreendê-lo, mas antes de, por assim dizer, ser compreendido, abarcado, absorvido por ele: de tornar possível o confronto com o que nele é incompreensível, inabarcável, inabsorvível. Que tal aconteça depende, pois pode não acontecer, da criticabilidade-traduzibilidade do objeto criticado-traduzido. É o que Benjamin exprime, numa passagem decisiva para este nosso ensaio, nos termos de um inevitável paradoxo.

Até que ponto pode uma tradução corresponder à essência desta forma, é objectivamente determinado pela traduzibilidade [Übersertzbarkeit] do original. Quanto menos valor e dignidade tiver a sua linguagem, quanto mais ela for comunicação, tanto menos terá com isso a ganhar a tradução, até que a preponderância completa daquele sentido, longe de ser a alavanca para uma tradução plenamente conforme a ele, acaba por fazê-la malograr. Quanto mais elevada for uma obra, tanto mais ela permanece ainda traduzível, no contacto fugidio com o seu sentido. (1990 [1923], p. 20)

Que a acepção especificamente benjaminiana da tarefa do tradutor nos permita reconhecer como a atividade do crítico permanece irredutível à do juiz e à do hermeneuta revela-se, em toda a sua plenitude, neste "paradoxo". Quanto mais insuscetível de ser comunicado ou interpretado, quanto mais rebelde ao sentido - quanto mais enigmático - é o objeto criticado-traduzido, tanto mais ele se revela a um só tempo criticável e traduzível. Pois 
tanto mais ele obriga o crítico-tradutor a sugerir vias de alargamento da língua de chegada - a do espectador - em que a sua tarefa se cumpre.

\section{4.}

De tudo isto decorre que atividade e passividade se encontram entrelaçadas na tarefa do crítico-tradutor. Mas não o estão já na "tarefa" do espectador? O que as distingue nesse caso? Não é o crítico-tradutor também um espectador? E não é o espectador, também ele, um tradutor, um espectador-tradutor? O que pode o crítico acrescentar à experiência do espectador se este já traduz?

Que o espectador seja um tradutor - e que reconhecê-lo enquanto tal seja a chave da questão da emancipação do espectador - parece ser justamente a tese de Rancière em " $O$ espectador emancipado". Com efeito, lemos à beira do final deste ensaio que "uma comunidade emancipada é uma comunidade de contadores e de tradutores" (2008, p. 29). Eis o argumento: não se trataria de emancipar o espectador..., de reunir as condições necessárias para resgatá-lo à passividade, para torná-lo ativo, desperto, consciente. O que este afã pressupõe, ainda que tacitamente, é a equação entre ser espectador e ser passivo. Ora, é precisamente contra esta pressuposição que, segundo Rancière, urge repensar a emancipação do espectador - e não a emancipação do espectador pelo artista ou, já agora, pelo crítico:

[A] emancipação começa quando se põe em causa a oposição entre olhar e agir, quando se compreende que as evidências que estruturam as relações do dizer, do ver e do fazer pertencem elas mesmas à estrutura da dominação e da sujeição. Ela começa quando se compreende que olhar é também uma acção que confirma ou transforma essa distribuição de posições. $\mathrm{O}$ espectador também age, como o aluno e o erudito. Ele observa, selecciona, compara, interpreta. (2008, p. 19)

Deste ponto de vista, uma arte desejosa de emancipar o espectador pode ser uma arte incapaz de reconhecer o que torna possível essa emancipação: a atividade do espectador enquanto espectador - atividade que Rancière caracteriza, a páginas tantas, como "poder que cada um ou cada uma tem de traduzir à sua maneira o que percepciona, de o ligar à aventura intelectual singular que torna cada espectador semelhante a qualquer outro, na justa medida em que a sua aventura não se parece com a de mais ninguém" (2008, p. 23 [itálico nosso]). Que, no texto de Rancière, o reconhecimento da atividade do espectador coincida com a ideia de que o espectador é, também ele, um tradutor reconduz-nos ao propósito destas páginas. Tal como n'“O espectador emancipado" está em discussão, parafraseando Rancière ${ }^{7}$, o reconhecimento da atividade em jogo na experiência do espectador, tratar-se-ia agora de reconhecer a passividade inerente à experiência do crítico. Em ambos os casos, a ideia de tradução permitiria subtilizar a análise. No primeiro, para fazer justiça à atividade do espectador - que observa, selecciona, compara, interpreta e traduz. No segundo, para dar conta da passividade do crítico que, submetendo-se à lei do objecto criticado, faria "menos" do que prescrever ativamente a regra pela qual se haveria de julgá-lo, ainda que "mais" do que descrever passivamente a sua estrutura ou as circunstâncias da sua realização.

Entretanto, permitindo clarificar o propósito deste texto, o paralelo com o ensaio de Rancière também dá ensejo à formulação de uma série de questões incontornáveis. Se o próprio espectador é um tradutor, de que lhe serve a tradução do crítico? O que acrescenta,

\footnotetext{
${ }^{7}$ Nas palavras do próprio: “[n]ão nos cabe transformar os espectadores em actores e os ignorantes em sábios. Cabe-nos reconhecer o saber latente no ignorante e a actividade própria ao espectador” (2008, p. 24). 
como há pouco escrevemos, o exercício do segundo à experiência do primeiro? Em suma, o que é que singulariza - e justifica - a tarefa do crítico-tradutor, acerca da qual está ainda por saber se estabelece uma "mediação" entre a linguagem do artista e a linguagem do espectador-leitor-ouvinte?

Reconheça-se antes de tudo que, se todo o crítico é um espectador, um leitor ou um ouvinte, nem todo o espectador é um crítico. Quer dizer, que todo e qualquer espectador seja, tal como o crítico, um tradutor não significa que traduza tal como o crítico traduz: ao crítico cabe também escrever. E escrever - é o que cumpre precisar à luz do conceito benjaminiano de tradução - desdobrando a criticabilidade-traduzibilidade do objeto criticado-traduzido. $\mathrm{O}$ que distingue o espectador-tradutor do crítico-tradutor não é portanto a posse de um saber que firmaria a autoridade do crítico pelo preço de lhe empobrecer a atividade - mas o exercício da escrita, com tudo o que a escrita, no caso do crítico-tradutor, pressupõe: o desdobramento do que resiste ao sentido no objeto criticado-traduzido por mor do alargamento da "língua de chegada". Ora, para que a "língua de chegada" seja a de quem quer que seja, não pode ser a de alguém em particular (a começar pelo próprio crítico). Neste sentido o crítico torna comum o que pode vir a ser, mas não deve ser de antemão, pessoalíssimo. O crítico seria, num último volte-face kantiano, uma espécie de tradutor desinteressado..., um cuja tradução não está ao serviço da sua própria "aventura intelectual", mas se presta à apropriação por qualquer um, a servir de móbil para a "aventura intelectual" de qualquer um.

Podemos finalmente responder à questão sobre se o "crítico-tradutor", distinto do "crítico-juiz", seria uma espécie de mediador entre a "linguagem" das artes e a "linguagem" dos seus espectadores, leitores e ouvintes. Se o for - é o que se tornou entretanto claro - não o será enquanto detentor de um qualquer saber, independentemente de este visar a intenção do artista, o sentido da obra, ou - chegados aqui - o efeito previsível ou desejável sobre o espectador. Em suma, afirmar que o crítico traduz significa afirmar que ele não se limita a julgar; significa pôr o acento na passividade do crítico, naquilo que no exercício da crítica permanece irredutível à atividade judicativa. Mas afirmar que o crítico traduz, à luz do modo como Benjamin entendeu a tarefa do tradutor, significa ainda distingui-lo quer do críticointérprete quer do crítico-estratega. A tarefa do crítico jogar-se-ia à margem de qualquer saber normativo, compreensivo ou pragmático. O que o crítico-tradutor promove - e é nesse sentido que se pode pensá-lo como um mediador - é o prolongamento de uma experiência do objeto artístico em que o próprio redesenhar da fronteira entre o saber e o não saber permanece em jogo quer para o crítico quer para quem venha a ler a crítica. É, sobretudo, o eco de uma vertigem, de um abalo, de um choque - de um obscurecimento do sentido - o que o críticotradutor restitui e passa à escrita.

5.

Nada disto - por surpreendente que pareça agora dizê-lo - obsta a que o crítico também avalie as práticas e os objetos artísticos do ponto de vista que mais se lhe afigurar pertinente. Tal como se espera que os contextualize e interprete se necessário. Ou até que reflita sobre os seus potenciais efeitos. O que se contesta não é que o crítico possa e deva fazer um pouco de tudo isto - quer esteja em causa um ensaio ou uma peça jornalística -, mas que o enfoque numa destas atividades permita ir ao âmago da questão. $\mathrm{O}$ que assim se pretende é prevenir que, a pretexto de uma muito necessária revalorização da crítica, se recaia em dicotomias como a que opõe as dimensões judicativa e interpretativa da crítica de arte. Nem uma nem outra, tampouco uma mistura das duas, captaria o gesto mais íntimo do crítico: desdobrar - 
traduzir noutra "língua" - o que não espera ser nem ajuizado nem interpretado, não porque contenha um saber supremo ou indizível, mas porque escrevê-lo é ainda mostrar que o seu sentido é traduzível somente por força da sua indecidibilidade e que é como tal, na sua radical abertura, que merece e exige ser apropriado por qualquer um.

\section{Referências bibliográficas:}

AGAMBEN, G. Altissima povertà. Regole monastiche e forma di vita. Milano: Neri Pozza, 2011.

BAUDELAIRE, C. À quoi bon la critique? Salon de 1846. Euvres complètes. Paris: Robert Laffont, 2001, p. 640-642.

BENJAMIN, W. Der Begriff der Kunstkritik in der deutschen Romantik [1920]. In:

Gesammelte Schriften, v. 1, 1. Frankfurt am Main: Suhrkamp, 1990. p. 78-79.

. "Die Aufgabe des Übersetzers" [1923]. In: . Gesammelte Schriften, v. 4, 1. Frankfurt am Main: Suhrkamp, 1990. p. 15.

Curriculum vitae. In: . Sobre Arte Técnica, Linguagem e Política. Lisboa:

Relógio d'Água, 1992. p. 232.

FOUCAULT, M. Qu'est-ce que la critique? Critique et Aufklärung. Bulletin de la Société française de philosophie, t. LXXXIV, p. 35-63, 1990.

MOLDER, M. F. O Químico e o Alquimista. Lisboa: Relógio d'Água, 2011.

RANCIÈRE, J. Le spectateur émancipé. Paris: La fabrique, 2008.

SARDINHA, D. L'émancipation de Kant à Deleuze. Paris: Hermann, 2013. 